\title{
La industria del sexo, los migrantes y la familia europea*
}

\author{
Laura Ma Agustín**
}

\begin{abstract}
Resumo
Este artículo demuestra como el uso de categorías como prostitución, turismo sexual y "tráfico", por parte de representantes de gobiernos, proyectos sociales y académicos, borra la diversidad entre las situaciones e impulsos de la gente que viaja, participa en redes que facilitan los viajes y vive del comercio sexual. Así se reproducen discursos estigmatizantes y controladores que justifican intervenciones de los que quieren "ayudar" pero que entienden muy poco de lo que pasa sobre el terreno. Estos discursos también esquivan la colaboración de los europeos en la problemática de la migración: turistas que quieren disfrutar de sus vacaciones, que pueden formar vínculos afectivos con "nativos" y que cada vez más quieren pagar a gente de fuera por servicios domésticos, de cuidado y sexuales en Europa.
\end{abstract}

Palavras-chave: Prostitución, Turismo Sexual, Tráfico, Trabajo Sexual, Gubernamentalidad.

\footnotetext{
* Publicado En GuAsCH, O. y Viñuales, O. (coords.) Sexualidades: Diversidad y Control Social. Barcelona, Editorial Bellaterra, 2002. A editora dos cademos pagu agradece a autora pela autorização para reproduzir este artigo.

"Pesquisadora asociada, "Regulating the Spaces of Sex Work", un proyecto colaborativo de tres universidades (Loughborough, Strathclyde y London South Bank) y financiado por el Economic and Social Research Council (RU). laura@ nod050.org
}

cadernos pagu (25), julho-dezembro de 2005, pp.107-128. 
La industria del sexo

The Sex Industry, Migrants and the European Family

\begin{abstract}
When academics and social agents use categories such as prostitution, sex tourism and 'trafficking', they erase the diversity of projects and impulses that are found among people who travel to work, who facilitate travels to work and who live from the sex trade. This erasing in turn reproduces stigmatizing and controlling discourses that justify interventions by those who want to 'help' but who understand very little of what actually goes on in the ground during migration processes. These discourses also fail to examine how Europeans participate in migration questions: tourists who want to enjoy their holidays, who may become fond of 'natives' and who more and more often wish to pay others for domestic, caring and sexual services in Europe.
\end{abstract}

Key Words: Prostitution, Sex Tourism, Trafficking, Smuggling, Sex Work, Governmental. 
Laura Ma Agustín

...algunas relaciones entre guías y turistas asumen otras características. Félix tenía una pequeña lista de direcciones de turistas con las que llevaba años de amistad... La mayoría de esta lista eran mujeres con las que había viajado por la isla. A l principio de tales viajes, declararía el precio de su compañía, pero si le llegaba a gustarle su compañera, le diría que ella podría regalarle cualquier cosa que quisiera. Por supuesto, ya habría disfrutado de varios días de viaje, buena comida, buen alojamiento y probablemente sexo, pero distinguía él entre ese tipo de relaciones y un arreglo directamente comercial. Como se ha reconocido en otras culturas, tales relaciones con extranjeros pueden tener un significado psicológico muy profundo que términos como "buscón" y "prostituto" no describen adecuadamente. ${ }^{1}$

Introducción

Entre los temas relativos a la "prostitución", usualmente se abordan los más melodramáticos: la pobreza del "tercer mundo", el "tráfico" de seres humanos, la violencia, la esclavitud, las enfermedades, la estigmatización, la marginación, la injusticia y el sufrimiento. No planteo ninguno de éstos en este ensayo. Tampoco intento explicar por qué existe la "prostitución", ni definirla ni juzgarla; y sobre to do no pretendo entrar en la polémica de si algún ser humano puede "elegir" el ejercerla. Mi trabajo a largo plazo es uno de deconstrucción, y lo principal que deconstruyo es un concepto, la "prostitución", inventado hace sólo dos siglos, sobre cuyo sentido ni los estudios ni los agentes sociales nunca han podido llegar a un acuerdo. Se supone que engloba tantas actividades que al final es mejor prescindir de la palabra. De todas maneras no pienso en la industria del sexo sólo en términos de los trabajadores; en cambio, ya que la mirada obsesiva siempre se ha dirigido hacia ellos (o mejor dicho, ellas)

\footnotetext{
${ }^{1}$ CRICK, Malcolm. Life in the Informal Sector: Street Guides in Kandy, Sri Lanka. En Harrison, David. Tourism and the Less Developed Countries. Londres, Belhaven Press, 1992, p.142 (traducción mía).
} 
La industria del sexo

prefiero señalar otros asuntos, sobre todo la existencia y la naturaleza de un mercado sexual.

Mientras la mayoría de los trabajadores sexuales es femenina, cada vez los que estamos en los ambientes conocemos más hombres, transexuales y transgenéricos. Sus servicios pueden tener un carácter homosexual, heterosexual o alguna posición intermedia. Los servicios sexuales son demandados también por las mujeres y personas trans, y no sólo por los hombres; también son demandados por los trabajadores sexuales. En una industria que se caracteriza por sus ambigüedades, es conveniente no perpetuar el supuesto clásico de mujer-sexoservidora/hombrecliente.

La cuestión del trabajo de niños y niñas entra en cualquier problematización de la industria del sexo. Se entiende que la niñez es una construcción social que no tiene el mismo sentido en distintas culturas del mundo. Sin embargo, para poder discutir sobre el trabajo, la explotación infantil y los derechos de los niños, la ONU y otros organismos internacionales han concordado en una definición del niño como persona con menos de 18 años. Los migrantes en Europa vienen de culturas en las que es común que los niños, sobre todo los adolescentes, trabajen, mientras en las sociedades receptoras el trabajo infantil está prohibido (con una leve variedad de edades definitorias). Un resultado es que hay migrantes en Europa que técnicamente hacen trabajo infantil y/o "prostitución infantil", también denominado "la explotación sexual de los niños". 2

Los trópicos: sitios de vacaciones y de salidas

Empiezo pintando un poco del ambiente en el que me encontraba cuando decidí por primera vez estudiar estas migraciones y su relación con la industria sexual. Me sentaba en un café de un pueblo en la parte oriental de Dominicana. Es un

\footnotetext{
2 OIT. Action against Trafficking and Sexual Exploitation of Children. Ginebra,
} Organización Internacional del Trabajo, 2001. 
lugar típico de los trópicos - es decir, el sitio más querido de medio mundo para sus vacaciones - pero todos los dominicanos a mi alrededor parecían estar hablando de la forma de salir de allí. A unos pocos kilómetros, las playas estaban llenas de alemanes, canadienses y españoles; en el café los dominicanos contaban lo que sabían acerca de las posibles maneras de llegar a Europa. En ese momento, mi trabajo era escucharles. Trabajaba en una organización nogubernamental dominicana con trabajadoras sexuales, clientes y dueños de bares en programas que más 0 menos tenían que ver con la prevención del SIDA y de las enfermedades de transmisión sexual. La parte médica era la que recibía el grueso de los fondos, pero siempre queríamos hacer otras cosas en la línea de "organizar" o educar a los trabajadores. La enorme discrepancia entre lo que decían los europeos que nos financiaban acerca de la gente "pobre" y lo que la gente pobre proponía hacer por su cuenta me parecía demasiado importante para no investigar.

En ese café, un joven camarero empezó a charlar conmigo y pronto me preguntó si yo podía ayudarle a llegar a Europa a cambio de cualquier tipo de servicios que quisiera. Muchos europeos que han viajado a países pobres han tenido esta experiencia; algunos recordarán todavía la simpatía que sentían y su deseo de colaborar. Algunos habrán ayudado con dinero, ideas - contactos; entre ellos algunos habrán aceptado experiencias sexuales a cambio. De este grupo, algunos habrán sentido cariño por la persona que se suponía (quizá después) que se llamaba "gigoló" o "prostituta".

Muchos habitantes de las lindas playas y los cascos históricos conocen a los turistas durante sus vacaciones, cuando todos parecen sofisticados y abiertos a posibilidades afectivas y sexuales. Los visitantes se enamoran, se relacionan y hacen planes para el futuro; muchos invitan a sus nuevas amistades a Europa. ${ }^{3}$

\footnotetext{
3 Seabrook, Jeremy. Travels in the Skin Trade. Londres, Pluto Press, 1996; CRICK, M. Life in the Informal Sector... Op. cit.; WALKER, Dave y EHRLICH,
} 
Se dan casos de turistas que se convierten en facilitadores de viajes y hacen buen negocio con ello. Todo parece llevar a viajes al exterior.

Sin embargo, en Europa estos migrantes encuentran que, a pesar de las oportunidades laborales abundantes, ellos mismos son despreciados, lamentados, acosados y ninguneados, a veces más que en sus propios países. Se preguntan: ¿Por qué los europeos les facilitan viajes para luego satanizarles, cazarles y deportarles? ¿Por qué los que quieren ayudarles ofrecen preservativos en vez de lo que realmente importa: consejos sobre cómo convertirse en "legal"? ¿No se decía que Europa era más progresista que el "tercer mundo"?

Yo vivía cerca de la zona colonial de Santo Domingo, con sus tiendas de artesanía y sus restaurantes para turistas. Siempre andaban muchas parejas compuestas de una persona blanca y una morena, y muchas veces pensé lo mismo: que los que ven en esta relación solamente la explotación por parte de un hombre rico a una mujer pobre no captan todo el cuadro. A menudo observaba a una mujer fuerte que guíaba y dirigía a un hombre, que le explicaba y le traducía su cultura, que le pedía su comida y aseguraba que no le robaran. Era normal ver a turistas con caras de angustia, cansancio o inseguridad y a nativas cuyos rostros lucían confianza, placer o aburrimiento. No toda pareja se veía igual, pero muchas rompían el estereotipo de un hombre blanco que domina a una mujer negra. También se veían cada vez más parejas en las que era la mujer la turista y el hombre el nativo así como parejas de dos hombres, de dos mujeres y de colores mixtos. El ambiente comenzaba a estar en todos lados a todas horas. $^{4}$

Richard. Hello My Big Big Honey: Letters to Bangkok Bar Girls and Their Revealing Interviews. Bangkok, Dragon Dance, 1992.

"Me refiero a la ambigüedad del mundo del "turismo sexual". A quienes estudiamos el temas nos parece que la etiqueta es inútil. Ver el epígrafe de Malcolm Crick. 
En varios puntos de Dominicana algunas personas se presentan como compradores de viajes. Quieren que ciertos vendedores se les acerquen para hacerles ofertas; sin embargo, esta situación se está denominando "tráfico de personas" en la comunidad internacional. Allí conocí a Lucía, que bailaba en un bar; me contó en detalle las propuestas que había recibido hasta la fecha. Había rechazado todas ellas porque exigía condiciones específicas. Por ejemplo, le habían ofrecido un "paquete" completo ${ }^{5}$ a buen precio pero para Suiza y no para Francia, que era su destino preferido; otro le habría llevado a París pero por un precio demasiado elevado. Desde el punto de vista de Lucía, nadie le estaba traficando; al contrario, ella estaba utilizando agentes de viajes, sólo que no podía recurrir a las agencias "normales". Se consideraba una consumidora inteligente, y hay muchas personas como ella.

Otra opción es viajar en etapas. Desde la costa oriental de la isla salen para Puerto Rico barquitos llenos de gente que ha decidido arriesgarse a un viaje peligroso. El Canal de Mona se navega con dificultad y en él viven muchos tiburones, mientras los barcos son livianos y viejos y van sobrecargados. A pesar de que to do el mundo conoce a alguien que se ha muerto en este viaje, las lanchas salen a menudo. Si logran esquivar el control oficial en la costa occidental de Puerto Rico, algunos viajeros se quedan allá, mientras otros continúan a otras islas caribeñas, a Miami, a Nueva York o a Europa.

\footnotetext{
${ }^{5}$ Los paquetes pueden incluir varios de, 0 todos los elementos siguientes: pasaporte con la identidad verdadera del viajero o con una identidad falsa; contrato para trabajar en un negocio específico en el extranjero; permiso de trabajo en el país de destino; visado para ese país basado en los elementos anteriores; billete de avión; cantidad adecuada para enseñar a oficiales de la inmigración en el país de entrada; ropa apropiada o consejos para vestirse correctamente; asesoramiento sobre cómo se debe contestar a las preguntas de los oficiales, sobre todo si se va a presentar como turista (enterarse, por ejemplo, cuáles son los monumentos principales, dónde esta la costa o la capital, etc.)
} 
En mi trabajo en una ONG de Santo Domingo escribía propuestas; una de las cuales se dirigía a personas que querían viajar a Europa. La contradicción frustrante era que buscábamos dinero de los holandeses y a los holandeses les interesaban sólo proyectos que cabían en su política de entonces, la cuál era, por una parte, animarnos a producir propuestas necesarias para la gente que conocíamos pero, por otra, la de desanimar los viajes a Holanda. Nosotros sabíamos que no íbamos a frenar ningún viaje al exterior dadas las condiciones reinantes tanto económicas como culturales, pero teníamos la oportunidad de educar a los viajeros para que sus experiencias no resultaran desastrosas. Era un trabajo delicado, el de redactar una propuesta realista, por ejemplo, incluyendo la información de que la embajada holandesa (al igual que la suiza, la española y las demás) aprobaba to dos los días solicitudes de visados para bailarinas y artistas. Los agentes (buscones, coyotes, prestamistas) que habían vendido sus paquetes a viajeros potenciales a menudo entregaban a las embajadas el papeleo de numerosas personas a la vez, lo cual quiere decir que los funcionarios sabían perfectamente de qué se trataba. Lo que queríamos explicar a los viajeros potenciales era su responsabilidad de revisar bien los contenidos de los paquetes y de no confiarse por la simple presencia de un visado oficial. Pero se decidió que no podíamos meter en la propuesta una advertencia sobre la complicidad de las embajadas. Al final la propuesta de educación para viajeros quedó medio vacía de las cosas en las que creíamos.

Otra agencia proporcionaba los fondos para hacer una película sobre la experiencia de trabajar en la industria sexual de Amsterdam, e insistía en hacerla tremendamente negativa, con redadas violentas, violaciones y miseria en todos lados, con la esperanza de que así se desanimarían los viajes. La mayoría concuerda en que la película [Me duele el alma ${ }^{6}$ ] no desanima a

\footnotetext{
${ }^{6}$ Krom, Frank. Me duele el alma (película). Cesar Messemaker/Lumen Film Productor, 1993.
} 
casi nadie, primero porque los que la ven son lo suficientemente sofisticados como para captar que es muy exagerada, y segundo porque todos conocen a alguien que no haya tenido ese tipo de experiencia horrible. $Y$, claro, cada viajero cree que él se contará entre los más afortunados: es una condición imprescindible para viajar. Pero el guión más realista que se había propuesto no fue financiado.

Migrantes transnacionales: migrantes múltiples veces

Con películas educativas, o solamente con sueños, los migrantes vienen cada vez más a Europa. En el "tercer mundo", los trabajos asequibles a las mujeres son a menudo domésticos y sexuales; ya que los mismos trabajos están disponibles también en Europa con pagos muy superiores, el proyecto de viajar tiene sentido. Para la mayoría de los hombres de tales países que viajan a Europa, los trabajos disponibles son a menudo la venta en el mercado negro o los de "peones", por ejemplo, en la construcción. Los sueldos que se pueden conseguir en la industria del sexo son más altos que en muchos otros trabajos: significan la posibilidad de ayudar a los parientes, meter a los hijos en la escuela, construir casas, poner pequeños negocios o vestirse como reinas. Pero además de los factores económicos que pueden impulsar a estos migrantes, existe el deseo de conocer el mundo, ser artista, independizarse o casarse, vivir en buenas casas y comer bien - los sueños de personas de todas partes del mundo, incluyendo Europa. Es también importante señalar que entre los que sufren la pobreza, malos matrimonios y todo el abanico posible de factores causales, no todos optan por migrar $y$, entre los que migran, no todos optan por el trabajo sexual. Ningún tipo de determinismo explica por completo el fenómeno humano de la elección. Toda opción se ve intervenida por cuestiones de clase, género, etnia y nivel económico, por las condiciones sociales del momento (guerra, dictadura, hambruna, violencia, paro, etc) y por 
la naturaleza del individuo, de sus deseos, sus pasiones, su aburrimiento, su curiosidad y su capacidad de arriesgarse.

El fenómeno de los migrantes que trabajan en la industria del sexo se puede entender en el marco de los procesos de globalización pero tiene un rasgo especial: es normal que estos viajeros no se asienten en un lugar a vivir sino que sigan viajando. Al trabajador sexual que hoy encuentras en Madrid puedes encontrarle mañana en París, el próximo mes en Ámsterdam y al año de vuelta en España. Y no es el resultado sólo de esfuerzos por esquivar los controles policiales o porque son trasladados de sitio en sitio por agentes intermediarios. Existe una cultura entre estos trabajadores en la que se quiere conocer Europa y en la que todos tienen sus lugares preferidos. Aunque son a menudo pobres e ilegales, muchos migrantes viajan de manera cosmopolita. ${ }^{7} Y$ aunque los estudiosos de las diásporas y de la transnacionalidad, en su gran mayoría, no han incluido a este grupo de migrantes en sus trabajos, la omisión no tiene justificación. ${ }^{8}$

Hoy en día se acepta que no se puede saber mucho, numéricamente, sobre las migraciones de carácter irregular, es decir, en las que se utiliza mucha documentación falsa y técnicas "informales" para moverse y mover a la gente. Cuando los migrantes se orientan a trabajos sexuales, es aún más difícil. Sus respuestas a la pregunta "¿De dónde viene?" pueden o no ser verdaderas, ya que a muchos de ellos les habrán cambiado la nacionalidad u otro aspecto de su "identidad" oficial como parte

\footnotetext{
7 Morokvasic. Birds of Passage Are Also Women... International Migration Review no 4, 1984, pp.886-907; Pettmman, Jan Jindy. Writing the Body: Transnational Sex. En Youngs, Gillian. Political Economy, Power and the Body. Londres, Macmillan, 2000, pp.52-74.

8 De los autores más famosos que estudian las diásporas y la transnacionalidad, sólo Arjun Appadurai ha escrito algo relacionado con el trabajo sexual, refiriéndose a una película (APPADURAI, Arjun. Modernity at Large. Minneapolis, University of Minnesota Press, 1996, pp.38-9 y 61-3). No salen en las obras de Homi Bhabha, Néstor García Canclini, J ames Clifford, Walter Mignolo, Edward Said, Avtar Brah y Fernando Coronil, por ejemplo.
} 
del "paquete". No confían en ningún encuestador ni en muchos agentes sociales. El concepto europeo de "la solidaridad" fácilmente se les escapa.

De hecho, la "solidaridad" de los del "primer mundo" también se debe problematizar, ya que causa bastantes contradicciones. Un ejemplo: estaba yo un domingo en una iglesia de Ámsterdam donde se dan misas en castellano a las que casi siempre acuden algunos miembros de la comunidad de trabajadores sexuales latinos, con sus familias, usualmente en la primera fila. (Otros componentes de la congregación son españoles exiliados durante la dictadura, comerciantes de Otavalo (Ecuador) y turistas.) La ponente del día era una monja que acababa de volver de pasar unos meses en el Caribe, y después de contarnos las crueldades de la pobreza allí, sacó de su bolso materiales educativos dirigidos a los que trabajaban en la zona roja e hizo una llamada a favor de su derecho a auto-denominarse trabajadoras sexuales (en vez de "prostitutas") y a sentir "autoestima" en el trabajo. La actuación de la monja no fue muy acertada, ya que los domingos son los únicos días no laborables para muchos de los que trabajan en Ámsterdam, en los que pueden disfrutar de una de sus pocas oportunidades de ser "respetables" en público. En esta ocasión, los latinos reaccionaron como si no tuvieran nada que ver con lo que pasaba. Las intenciones tan excelentes y la valentía personal de esa monja se encuentran a menudo entre ciudadanos europeos que sienten la injusticia de las políticas de sus gobiernos hacia los migrantes y el "tercer mundo" en general. Se unen a grupos y proyectos de carácter solidario, pero cuando los migrantes trabajan en la industria del sexo resulta ser una problemática especial.

El mundo de los proyectos

Los programas de solidaridad y ayuda casi siempre dirigen sus esfuerzos hacia los trabajadores de la calle, planteando que son los más necesitados. Vale decir, sin embargo, que este grupo 
es el único al que les parece posible acercarse con cierta facilidad y seguridad. La "metodología" de hablar sólo con los que trabajan en la calle omite a todos los demás que trabajan en burdeles 0 casas de citas, clubes de alterne, bares, cervecerías, discotecas, cabarets y salones de cóctel; en líneas telefónicas eróticas o en sexo virtual por Internet; en sex shops con cabinas privadas; en casas de masaje, de relax, de desarrollo del "bienestar físico" y de sauna; en servicios de acompañantes (call girls, chicos de alquiler) $\mathrm{y}$ en agencias matrimoniales; como actores en cine, video y revistas pornográficos; en restaurantes eróticos, servicios de dominación o sumisión, en complejos turísticos y en pisos particulares. $^{9}$

En el mundo de los migrantes "irregulares", los que trabajan en todas las demás formas son mucho más numerosos que los callejeros, y corren a menudo más peligro que los de la calle justamente porque no están expuestos a la vista pública. Aunque no cuentan con información comparativa sobre los no-callejeros, muchos proyectos de investigación o acercamiento de calle a menudo extrapolan lo que aprenden en la calle a todos los demás trabajadores sexuales. Hablan de la "prostitución" sin distinguir entre las personas que trabajan a tiempo parcial, a tiempo completo u ocasionalmente, entre personas que comparten o dan dinero a sus novios, novias y/o "chulos" y las que no lo comparten con nadie, entre personas más jovenes y más viejas, y entre personas de distintas sexualidades o gustos sexuales. En términos internacionales esta tendencia a confundir todas las variedades significa fusionar las experiencias de personas tan distintas como guías de Sri Lanka, trabajadoras de burdel de Sudáfrica, chicos playeros jamaiquinos, mujeres de las vitrinas de Ámsterdam, muchachas de los bares de Bangkok, actores de porno de Budapest, callejeras transexuales de Brasil, mujeres de Kenia en

\footnotetext{
${ }^{9}$ Agustín, Laura. Trabajar en la industria del sexo. OFRIM Suplementos, $n^{\circ} 6$, Madrid, OFRIM, 2000, pp.155-172. www.nod050.org/mujeresred/laura_agustin1.html
} 
matrimonios temporales, "concubinas" chinas de comerciantes japoneses y gente de los puertos de Nueva Zelanda que vive una serie de relaciones fijas con marineros, por mencionar una parte mínima de la enorme variedad que se da en el mundo.

La confusión se nota en la Casa de Campo de Madrid, un parque muy grande donde muchos migrantes hacen sus ofertas a los clientes que pasan en coche. Cuando un investigador habla tanto con trabajadores de los grupos solidarios y las ONGs como con los trabajadores sexuales, se puede dar cuenta de que, a pesar de que no existe ningún problema obvio entre los dos grupos, sí existen contradicciones entre sus versiones de lo que está sucediendo en este lugar que pueden influir en la eficacia de los proyectos. Según los acontecimientos nacionales del momento, se puede encontrar a personas de América Latina, del Oeste de África y del Este de Europa. Para muchos de los trabajadores sexuales, las identidades regionales o étnicas son más importantes que los nombres de sus países; a veces muchas de las transexuales parecen venir incluso del mismo pueblo. Quienes hacen trabajo solidario y médico son españoles. Varios proyectos tienen "unidades móviles" que van a la Casa de Campo a ofrecer preservativos, senvicios e informaciones para los trabajadores sexuales. Los que saben que los vehículos se encuentran allí y quieren acercarse son todos bienvenidos, y pueden recibir unos cuantos condones la primera vez sin enseñar ningún documento. El resultado que hay que tener en cuenta cuando se conocen los informes de esos proyectos es que tienen contacto con un grupo bastante específico, del cual no solamente la mayoría son personas de la calle sino que también son aquellos que buscan algún tipo de servicio y no tienen miedo a acercarse.

Los proyectos son conocidos por repartir condones gratuitos. A pesar de que los trabajadores sexuales ya los tienen, no se niegan a aceptarlos (aunque en alguna ocasión también he visto eso). Pero no entienden por qué, si los solidarios realmente quieren ayudar a los migrantes, no hacen algo más "útil" sobre el único problema decisivo que todos comparten, la necesidad de 
La industria del sexo

regularizar su situación. En la película Cosas que dejé en La $\mathrm{H}_{\text {abana }}{ }^{10}$, la industria que fabrica documentos falsos juega un rol importante. Hacia el final una actriz cubana que no sale en la lista de créditos de una obra de teatro en la que ha actuado en Madrid (porque ha trabajado ilegalmente) habla con su novio. Dice: "Quiero papeles. Papeles auténticos, ¿entiendes?". Le contesta el novio: "Todos los papeles son auténticos, son to dos de papel".

Hubo aplauso rotundo por parte de unos segmentos del público cuando vi la película en un cine normal de Madrid; cuando la vi una segunda vez en un ciclo de películas "solidarias", la reacción fue negativa. Esa negatividad sostiene que la industria de los documentos falsos explota a los migrantes, pero el punto de vista de muchos migrantes es que les facilita y hasta les salva la vida, aún si a la vez les explota. El protagonista de la película, el novio de la actriz, vive de vender documentos a otros migrantes y de relacionarse amorosamente con españolas. Ambas actividades se ven por parte de muchas personas solidarias como "parasíticas", pero en la película el cubano es amable y amado.

Los que trabajan en los proyectos a menudo saben poco de cómo viven los trabajadores cuando no están trabajando. No distinguen entre los países de África y parecen confiar bastante en los reportajes sensacionalistas que salen con frecuencia en la prensa española. El resultado es la creencia en que todas son jóvenes bajo el control total de unos "mafiosos" que las traen a España, las mantienen en pisos y no les permiten ninguna libertad. Otra impresión que se puede escuchar es de que se ven muy graciosas y deben estar disfrutando mucho del cambio fascinante respecto de sus vidas en "África" - como si la mayoría no viniera de grandes ciudades posmodernas en sus propios países. Existe otro punto de vista, sin embargo, de los que están trabajando en la Casa de Campo, en el que se critica a los españoles por no poder hablar ni inglés ni francés, lenguas que la

\footnotetext{
${ }^{10}$ Gutiérrez Aragón, Manuel. (dir.) Cosas que dejé en la Habana (película). Gerardo H errero Tornasol F ilms/Sogetel Productor, 1997.
} 
gente del Oeste de África considera adquisiciones normales e imprescindibles de los ciudadanos del mundo. Si ahora están aprendiendo español es como tercer, cuarto o quinto idioma.

Esta diferencia de percepción sobre las necesidades de los migrantes es uno de los puntos importantes que quisiera destacar. Mi propósito no es el de culpar a los europeos sino de problematizar las actuaciones alrededor del fenómeno de la "prostitución migrante", que más o menos se puede describir como un deseo de "ayudar", incluso de "salvar" a estas personas del "tercer mundo" sin saber casi nada acerca de ellas. Hoy día, muchos españoles y españolas se sienten llamados a salvar a los migrantes de ciertos aspectos de sus propias culturas, por ejemplo, de sus hábitos sanitarios, de su "bajo nivel cultural", de sus "creencias mágicas" ${ }^{11} 0$ de ser víctimas de "redes mafiosas". Este impulso tiene el mismo tinte moralizador que caracterizaba los esfuerzos reformistas del siglo XIX respecto a la prostitución. Los agentes sociales proponen "proteger" a estas personas, a las que etiquetan de ignorantes e indefensas. Los sujetos de este discurso no se ven así, pasivos y coaccionados; el impulso de los que quieren ayudar vuelve a ser controlador. ${ }^{12}$

\footnotetext{
${ }^{11}$ Médicos del Mundo. CASSIM. Ofrim Boletín, n 31, Madrid, OFRIM, 2000, pp.12-13. Información muy básica sobre las otras culturas parece faltar en muchos de los proyectos. Tacharlas de "bajo nivel" es seguir en la misma línea de hace 500 años cuando los conquistadores vieron por primera vez a los indígenas del Nuevo Mundo. Desaprobar costumbres sanitarias comunes y corrientes en otros países (por ejemplo la de inyectarse medicamentos en vez de tomarlos en forma de pastillas) representa un prejuicio. No conocer el carácter de las religiones no occidentales lleva al occidental a decirlas "magia" 0 "superstición", sobre todo cuando se trata de rituales ajenos a los suyos. EI sacrificio de animales lo ve como "bárbaro"; un promesa jurada a un sacerdote 0 curandero lo ve como cruel servidumbre (que no necesariamente difiere tanto del ritual de la confesión católica). El choque cultural entre religiones ya está bien conocido en algunos países occidentales con poblaciones importantes de migrantes musulmanes, africanos, asiáticos o latinos.

${ }^{12}$ Weeks, J effrey. Sex, Politics and Society: The Regulation of Sexuality since 1800. Londres, Longman, 1981; ARMSTRONG, Nancy. The rise of the domestic woman. En Armstrong, N. y Tennenhouse, Leonard. The Ideology of Conduct.
} 
La industria del sexo

En Europa, sobre todo durante los últimos dos siglos, la "prostitución" ha sido construida como una transacción (sexo por dinero) que se desvía de la normalidad de la familia nuclear. Discursos médicos, sociológicos, criminológicos, psicológicos y feministas se han fijado en las "prostitutas" en vez de en los clientes y en las mujeres en vez de en los hombres. Se han centrado en los individuos aislados sin pensar que todos forman parte de alguna familia y que desempeñan papeles comunitarios. Y han tratado a estas personas como si lo único importante de ellas fueran ciertos órganos - la vagina, el pene - en vez de sus cuerpos enteros. En España ahora se habla de los trabajos sexuales bien como "tráfico de mujeres" (siendo conveniente pensar en extranjeros, criminales, negros, etc.) o bien como un problema de zonificación (acerca de si se les va a permitir seguir trabajando en ciertas zonas o no). En el primer caso los medios hablan con pena o lujuria de "víctimas engañadas". ${ }^{13}$ En el segundo, publican siempre la misma foto de una mujer inclinándose para negociar con alguien que está en su coche. Esa foto tan repetida realmente despista la mirada respecto a lo evidente: la existencia de un amplio mercado en España, al igual que en to da Europa, que desea pagar servicios sexuales.

Nueva York, Methuen, 1987, pp.96-141; Agustín, L. At Home in the Street: Questioning the Desire to Help and Save. In: Bernstein, E. and Shaffner, L. (eds.) Regulating Sex: The Politics of Intimacy and Identity. Perspectives on Gender. New York, Routledge, 2004, pp.67-82; y Helping Women Who Sell Sex: The Construction of Benevolent Identities. Rhizomes 10, special edition on $\mathrm{Neo-}$ Liberal Governmentality: Technologies of the Self \& Governmental Conduct. $\mathrm{H}$. Ren, ed. 2005. www.rhizomes.net

${ }^{13}$ Por ejemplo: SoRDo, Julen. Por fin vemos la luz del día: 8 ex-prostitutas que han salido del infierno. Marie-Claire (112), mayo 1997; PASCUAL, Ana María. Una colombiana que evitó la trampa de los proxenetas. Diario 16 [Sociedad 28], 16 ago sto 1997; BARRo So, F. J avier. Una deuda de horror. EI País, [Madrid 4] 21 de agosto, 1998; OLABE, Fernando y PIQUERES, Begoña. Sólo veinte minutos por cliente: la sórdida historia de chicas vendidas... etc. El Mundo, año ix, no 101, [Crónica 12], 21 de septiembre, 1997. 
Durante los últimos doscientos años en Europa, este grupo llamado "prostitutas" ha sido construido como personas que necesitan ser rescatadas. En los últimos cien años el rescate ha sido dirigido a algo que antes se llamaba "trata de blancas" y ahora se denomina "tráfico de mujeres" ${ }^{14} \mathrm{H}$ oy en día, incluso los que no hablan de "tráfico" suelen utilizar abstracciones teóricas tales como "violencia de género" o "explotación", conceptos valoradores de por sí de situaciones muy complejas. ${ }^{15}$ Los enfoques que se dan en España son todavía de fuerte carácter moralizador. Parten de suposiciones sobre el lugar "correcto" del sexo (la casa de una pareja), sobre las "buenas" formas del sexo (con "amor", en pareja y sin dinero) y sobre los conceptos occidentales acerca de la clase media, poco fáciles de imponer a personas de otras culturas (por ejemplo, la identidad personal o el yo, la autoestima, la dignidad del trabajo). Estos enfoques sólo se pueden seguir manteniendo mientras nadie preste atención a los discursos de los sujetos implicados.

Existe otro argumento para no perpetuar la construcción de la prostitución como un solo tipo de relación (hombre poderoso/ mujer "desempoderada"). Law señala cómo esta representación ciertamente importante para demostrar las desigualdades

\footnotetext{
${ }^{14}$ La primera frase tiene su origen en un escándalo en el norte de Europa durante una larga migración de mujeres europeas hacia Argentina, un país receptor al que faltaban mujeres a fines del siglo XIX. Ya que no se quería creer que esas "blancas" pudieran elegir vender servicios sexuales, se creó un concepto conveniente. GUY, Donna. "White Slavery", Citizenship and Nationality in Argentina. En PARKER, Andrew et alii. Nationalisms and Sexualities. Londres, Routledge, 1992, pp.201-215; DoEzEMA, J O. Loose Women or Lost Women: The Re-emergence of the Myth of White Slavery in Contemporary Discourses of Trafficking in Women. Gender Issues, vol. 18, $n^{\circ} 1,2001$, pp.23-50.

${ }^{15}$ ALtink, Sietske. Stolen Lives: Trading Women into Sex and Slavery. Londres, Scarlet Press, 1995; Co IN. Viajes al exterior: llusiones y mentiras (Exportación de sexo organizado). Santo Domingo RD, Centro de Orientación e Investigación Integral, 1992; DoEZEMA, J. Loose Women or Lost Women... O p. cit.; FundACIÓN ESPERANZA. No pensé que eso me fuera a pasar: Prostitución y tráfico de mujeres latinoamericanas en Holanda. Amsterdam, Fundación Esperanza, 1998.
} 
La industria del sexo

económicas, políticas y sociales de las personas involucradas tiene a su vez el efecto de fijar las identidades de "opresor" y "víctima", convirtiéndolas en un discurso hegemónico en el que los sujetos encuentran poco espacio para maniobrar. ${ }^{16}$

El mercado del sexo

La clientela de esta industria, siendo invisibilizada por un discurso que se fija solamente en las servidoras, es incontable; sin embargo algunas fuentes han calculado que hasta un millón de hombres compran sexo todos los días en España. Incluso si esa cifra está equivocada, nunca pretendía incluir todas las modalidades que forman parte de la industria sexual sino solamente la "prostitución". H ay que tener en cuenta además que no serán los mismos clientes quienes acuden a los ambientes todos los días: los habrá que van una vez a la semana mientras que otros van más o menos, con una larga suma de personas al año que busca servicios sexuales. Estos servicios son, además, diversos, porque la clientela se compone de personas de todo tipo, edad, nivel económico, etnia, región y gusto y porque los servicios pueden tener un carácter homosexual, heterosexual, transexual o mixto. Los migrantes también son clientes.

Se dan entonces bastantes y variadas oportunidades para trabajar en esta industria. Para los migrantes que encuentran sus otras opciones desagradables, difíciles o mal pagadas (limpieza, servicio doméstico interno o externo, cuidado de ancianos, enfermos o niños), encontrar una situación en la industria sexual puede resultar interesante. Ya que muchas veces no tienen los papeles en regla, o que sus permisos de trabajo (como doméstica, por ejemplo) pueden estar basados en documentos falsificados, trabajar en un mundo lleno de irregularidades puede no parecerles más arriesgado. Pero, ¿qué es lo que dice la sociedad receptora

\footnotetext{
${ }^{16}$ LAW, Lisa. Dancing on the Bar: Sex, Money and the Uneasy Politics of Third Space. En PILE, Stephen y KEITH, Michael. Geographies of Resistance. Londres, Routledge, 1997, p.107.
} 
acerca de esta industria? (1) Que los que utilizan estos servicios son hombres pervertidos que no saben vivir una vida "normal" de familia; (2) que son machistas que, al no aguantar la creciente libertad de las mujeres, buscan formas de dominarlas; (3) que responde al aumento del consumismo en general, ya que ahora todo se convierte en mercancía; (4) que son porquerías extranjeras, o que forman parte del proyecto "Europa" o que es la "globalización"; (5) que es la presencia de prostitutas la que provoca el deseo, así que la culpa la tienen "esas mujeres viciosas" o (6) la tienen los mafiosos "rusos" que las traen (o senegaleses 0 colombianos, según el momento) o (7) la tienen las condiciones económicas injustas que fuerzan a las personas a salir de sus países para ganarse la vida. Son todas explicaciones negativas, basadas en la suposición de que el trabajo sexual es malo. Menos escuchadas pero algo más positivas son: (8) que en una democracia la gente tiene derecho a experimentar su sexualidad como libertad de expresión; (9) que si el acto sexual es "consensual" no hace daño a nadie; (10) que si los trabajadores cobran bien y se ganan la vida no hay ningún problema para nadie.

Entre estas explicaciones la única que cuesta trabajo creerla es la que etiqueta a los clientes como perversos o pervertidos. ${ }^{17}$ Son tantas las personas que pagan el sexo que es imposible que se trate de casos excepcionales. Al contrario, la abundancia de la demanda es exactamente lo que nos explica la presencia de tantas personas que trabajan en esta industria; los migrantes no vendrían a trabajar si no hubiera trabajo, si no hubiera quien quisiera sus servicios. Lo mismo sucede a las personas europeas que entran en el mercado sexual. ${ }^{18}$

\footnotetext{
${ }^{17}$ Sin embargo, cuando se aborda el tema usualmente se hace como "problema de hombres" y de casos individuales. Por ejemplo, CASAn Ova, Pilar. ¿Por qué se van a las prostitutas? Dunia [448] 1 junio 1997, pp.38-41.

${ }^{18}$ Nowak, Anna. Political Transformation in Poland: The Rise of Sex Work. Research for Sex Work, n², Amsterdam, Vrije Universiteit, 1999, pp.9-11.
} 
En España lo que sale en los medios de comunicación son casos de victimización, desgracia o fracaso. A la vez ha salido repetidas veces la noticia de que después de una redada las trabajadoras comentan que sólo quieren que se las deje en paz con su trabajo. Mientras tanto, el cliente y el mercado se hacen invisibles tanto en los medios como en los informes policiales. Vale examinar de qué se tratan tantas oportunidades para trabajar. La sociedad española sigue, a pesar de muchas formas de "apertura" y "modernización" en temas sociales, con el discurso de que la normalidad es la familia nuclear o la pareja (que ahora puede ser homosexual en ciertos sitios). Sin embargo, esa familia/pareja, sobre todo de la clase media, busca hoy en día en el mercado servicios tradicionalmente desempeñados por sus propios miembros: los servicios domésticos, de cuidado y sexuales. ${ }^{19}$

Aunque el estereotipo es el cliente masculino, la demanda de servicios sexuales existe no sólo entre hombres heterosexuales, sino también entre homosexuales, bisexuales, travestis, transexuales, mujeres heterosexuales y lesbianas. Si eso parece exagerado, conviene considerar los anuncios no sólo personales sino de sitios como New Boys Disco Top-Less Masculino (¡Dedicado a tí, mujer!) de las páginas amarillas de Madrid. ¿Que eso es sólo espectáculo? Lo mismo se dice sobre los topless para hombres. Dentro de los ambientes europeos, además, se habla del crecimiento de las clientas $s^{20}$, pero si todavía "no se ve bien" que la mujer vaya a comprar sexo en su propio país, es cada vez más convencional que lo haga en destinos turísticos como el Caribe, Indonesia 0 algunas costas de África. Allí cada vez más mujeres

\footnotetext{
${ }^{19}$ Agustín, Laura. A Migrant World of Services. Social Politics, 10, 3, 2003, pp.377-96.

${ }^{20}$ Comunicaciones personales durante investigaciones en Ámsterdam, Utrecht, Madrid, Pamplona, Londres, París y Roma. Además, en estudios del uso de páginas de pornografía y sexo comercial entre europeos, las cifras sobre mujeres como usuarias son muy importantes. Nielsen Netratings, published in Ciberpaís 9, Barcelona, March 2001, p.13.
} 
europeas tienen relaciones sexuales pagadas de una forma $u$ otra, relaciones en que puede haber 0 no sentimientos de cariño 0 amistad. ${ }^{21}$

Hay una conexión importante entre todas las variantes de turismo sexual y los migrantes que vienen a Europa. Bastantes investigaciones han demostrado cómo las relaciones afectivocomerciales conducen a menudo a invitaciones a visitar, trabajar y/o quedarse en Europa. ${ }^{22}$ Allí, en esas playas de contacto entre culturas, donde los deseos europeos de divertirse encuentran una multitud de ofertas, empiezan muchos viajes. Tampoco se trata de una serie de individuos sin conexión con ningún contexto social; por eso vale pensar en todos los beneficiarios de la industria sexual: empresas aéreas, de telecomunicaciones (móviles, beepers, contestadores) y de seguridad (guardianes, sistemas de alarma), productores de bebidas y tabaco, agencias de viaje, servicios de alquiler de coches y de taxis, abogados, médicos, camareros, modistas, peluqueros, propietarios, gerentes, proxenetas y más. Todas son personas con sus familias que viven de la industria. Tanto dinero está involucrado que la Organización Internacional del Trabajo ha recomendado su inclusión en la contabilidad oficial de gobiernos nacionales y regionales. ${ }^{23}$ Sin embargo, en España la industria todavía no es reconocida en su diversidad e impacto financiero, y los que trabajan en ella, ahora más de la mitad extranjeros, son tratados sólo como víctimas de varios tipos de engaño, y como niñas indefensas.

\footnotetext{
${ }^{21}$ De Albuquerque, Klaus. Sex, Beach Boys, and Female Tourists in the Caribbean. Sexuality and Culture, $n^{\circ} 2,1998$, pp.87-112.

${ }^{22}$ Coln. Viajes al exterior... Op. cit; O ppermann, Martin. (coord.) Sex Tourism and Prostitution: Aspects of Leisure, Recreation, and Work. Cognizant Communication, Cammeray AU, 1998; Kempado0, Kamala. Sun, Sex and Gold. Lanham MD, Rowman \& Littlefield, 1999.

${ }^{23}$ LIM, Lean Lin. (coord.) The Sex Sector: The Economic and Social Bases of Prostitution in Southeast Asia. Ginebra, Organización Internacional del Trabajo, 1998.
} 
La industria del sexo

Las maneras clásicas de abordar "la prostitución" no sirven para describir la realidad actual de la industria del sexo y sus trabajadores. ${ }^{24}$ Además son maneras que no incluyen los contextos sociales en los que existe la industria: familias que no conforman a la definición clásica del patriarca que trabaja mientras su mujer está en casa; familias dispuestas a pagar nuevos servicios; viajes turísticos al alcance a personas cada vez menos ricas; negocios globalizados y consumismo creciente. Los marcos clásicos tampoco examinan bien la actuación del mundo de los agentes sociales (funcionarios, policías, personal médico, investigadores y empleados de ONG s), los elementos imperialistas de varios discursos feministas y el papel negativo que juega la prensa. En vez de romper el silencio, se ha escuchado a menudo en las discusiones sobre las migraciones el argumento de que hablar de la "prostitución" como ocupación de los migrantes les "estigmatiza"; en múltiples estudios de mujeres migrantes en España se ha omitido el tema. ${ }^{25}$ Pero esa idea proporciona la excusa para hacerlas desaparecer de los discursos donde sus experiencias deberían ser centrales; se les quita to da capacidad de opción y decisión. De este modo, se facilita la perpetuación de su ubicación donde han estado durante mucho tiempo: los márgenes.

\footnotetext{
${ }^{24}$ Agustín, Laura. Trabajar en la industria del sexo, y otros tópicos migratorios. San Sebastián/País Vasco, G akoa, 2004; Y Lo no hablado: deseos, sentimientos y la búsqueda de "pasárselo bien". In: OSBORnE, R. (ed.) Trabajadoras del sexo: derechos, migraciones y tráfico en el siglo XXI. Barcelona, Bellaterra, 2004, pp.181-191.

${ }^{25}$ En 2001 se incluyó el tema en un estudio llevado a cabo para una entidad gubernamental, IMSERSO, de España, ahora publicado en AguSTín, L. Trabajar en la industria del sexo, y otros tópicos migratorios. Op. cit.
} 